\title{
SIDEBAR. Acoustic Backscatter Patterns
}

\author{
By Jaime Palter, Lauren Cook, Afonso Gonçalves Neto, Sarah Nickford, and Daniele Bianchi
}

Hidden from view beneath the ocean surface, an abundance of marine animals, many smaller than a centimeter long, assemble into distinct layers that can be continuous over thousands of kilometers of the ocean (Klevjer et al., 2016). These layers contain an enormous standing stock of biomass that is a key food source for a diversity of marine predators (Irigoien et al., 2014).

Acoustic methods have proven to be increasingly powerful tools for examining the behavior of these animals (Bianchi et al., 2013; Irigoien et al., 2014; Bianchi and Mislan, 2016; Klevjer et al., 2016). The backscatter strength of acoustic signals gives an indication of the density of these animals and their positions in the water column. Therefore, the repeat ADCP along CMV Oleander III transits provides a unique view of the space-time variability of these scattering layers.

The $75 \mathrm{kHz}$ acoustic signal used since 2005 detects centimeter-size macrozooplankton and micronekton, as well as organisms with inflated gas inclusions, which return the strongest echo. These critters include euphausiids, myctophids, and mesopelagic fish. Though the acoustics cannot inform us about the species composition of the backscatterers, we can learn much about their mobility and presence in different water masses throughout the year. Figure 1 provides an example from a transit with high-quality data return and fair weather throughout the passage from New Jersey to Bermuda. The acoustic backscatter profiles were processed by averaging in $8 \mathrm{~m}$ vertical bins, and in duration from three to five minutes. We use a bulk depth range correction to account for beam spreading and water absorption that follows the sonar equation described in Deines (1999).

For the transit depicted in Figure 1, the ship traveled through the night over the shelf. The sun rose when Oleander was approximately $150 \mathrm{~km}$ north of the Gulf Stream in the Slope Sea (top curve in the figure). Before sunrise, a dense sound scattering layer (SSL) congregates near the surface of the Slope Sea, about 150-200 km north of the Gulf Stream. As the sun rises, the SSL begins its daily dive, closely following the position of an isolume (depicted as a white contour) through the water column. Just before local noon, the ship crossed the Gulf Stream (indicated by the red isotach contours). Within the swiftest part of the current, there is anomalously low backscatter that extends to a depth of $600 \mathrm{~m}$. This abrupt reduction of scattering organisms is frequently observed in the Oleander crossing of the Gulf Stream, and may reflect the downstream advection of water with low backscatter content. To the south of the Gulf Stream, the deep scattering layer reappears along the same isolume as in the Slope Sea but-owing to the increased clarity of the Sargasso Sea Water-is almost 200 m deeper. The Sargasso Sea also hosts a shallower mesopelagic SSL centered at a depth of approximately $200 \mathrm{~m}$ that is not apparent north of the Gulf Stream.

The transit between the Gulf Stream and Bermuda takes over 24 hours, which is long enough to reveal a full cycle of diel vertical migration in the Sargasso Sea. As soon as the sun sets, some fraction of the animals from the deepest observed sound scattering layer at $500 \mathrm{~m}$ and the intermediate layer at $200 \mathrm{~m}$ swim upward and thicken the dense scattering layer near the ocean surface. At sunrise, the organisms dive again to deeper and darker layers. This pattern is coherent across the Sargasso Sea, with only one noticeable excursion: in a cyclonic eddy about $200 \mathrm{~km}$ south of the Gulf Stream (apparent in the red isotachs), the scattering layers all bend toward the surface, just as isopycnals would be expected to do in this feature (see Rossby et al., 2011). ๔

\section{REFERENCES}

Bianchi, D., and K.A.S. Mislan. 2016. Global patterns of diel vertical migration times and velocities from acoustic data. Limnology and Oceanography 61(1):353-364, https://doi.org/ 10.1002/Ino.10219.
Bianchi, D., E.D. Galbraith, D.A. Carozza, K.A.S. Mislan, and C.A. Stock. 2013. Intensification of open-ocean oxygen depletion by vertically migrating animals. Nature Geoscience 6(7):545-548, https://doi.org/ 10.1038/ngeo1837.

Deines, K.L. 1999. Backscatter estimation using Broadband acoustic Doppler current profilers. In Proceedings of the IEEE Sixth Working Conference, https://doi.org/10.1109/CCM.1999.755249.

Irigoien, X., T.A. Klevjer, A. Røstad, U. Martinez, G. Boyra, J.L. Acuña, A. Bode, F. Echevarria, J.I. Gonzalez-Gordillo, S. Hernandez-Leon, and others. 2014. Large mesopelagic fishes biomass and trophic efficiency in the open ocean. Nature Communications 5(1):3271, https://doi.org/10.1038 ncomms4271.

Klevjer, T.A., X. Irigoien, A. Røstad, E. Fraile-Nuez, V.M. Benítez-Barrios, and S. Kaartvedt. 2016. Large scale patterns in vertical distribution and behaviour of mesopelagic scattering layers. Scientific Reports 6(1):19873, https://doi.org/10.1038 srep19873.

Rossby, T., C. Flagg, P. Ortner, and C. Hu. 2011. A tale of two eddies: Diagnosing coherent eddies through acoustic remote sensing. Journal Geophysical Research 116(C12):C12017, https://doi.org/10.1029/ 2011JC007307.

Thomas, L.N., and T.M. Joyce. 2010. Subduction on the northern and southern flanks of the Gulf Stream. Journal of Physical Oceanography 40(2):429-438, https://doi.org/ 10.1175/2009JPO4187.1.

\section{AUTHORS}

Jaime Palter (jpalter@uri.edu) is Assistant Professor, Graduate School of Oceanography, University of Rhode Island, Narragansett, RI, USA. Lauren Cook recently finished her bachelor's degree at the University of South Carolina, Columbia, SC, USA. Afonso Gonçalves Neto and Sarah Nickford are both PhD Candidates in the Graduate School of Oceanography, University of Rhode Island, Narragansett, RI, USA. Daniele Bianchi is Assistant Professor, Department of Atmospheric \& Oceanic Sciences, University of California, Los Angeles, CA, USA

\section{ARTICLE CITATION}

Palter, J., L. Cook, A. Gonçalves Neto, S. Nickford, and D. Bianchi. 2019. Acoustic backscatter patterns. Oceanography 32(3):140-141, https://doi.org/10.5670/ oceanog.2019.321

\section{COPYRIGHT \& USAGE}

This is an open access article made available under the terms of the Creative Commons Attribution 4.0 International License (https://creativecommons.org/ licenses/by/4.0/), which permits use, sharing, adaptation, distribution, and reproduction in any medium or format as long as users cite the materials appropriately, provide a link to the Creative Commons license, and indicate the changes that were made to the original content. 
June 16, 2005

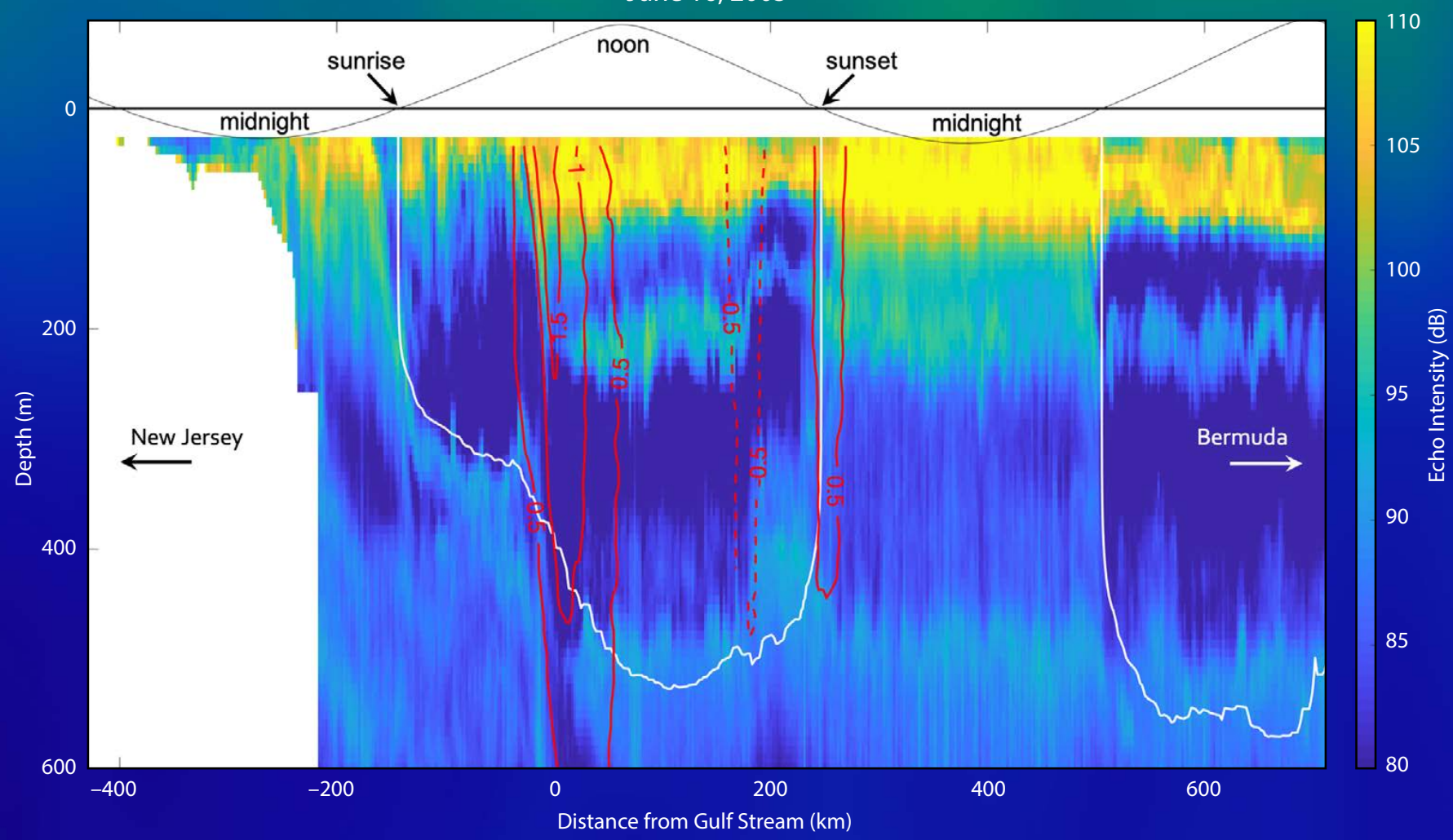

FIGURE 1. Acoustic backscatter intensity ( $\mathrm{dB}$, shown in color) versus depth and distance from the center of the Gulf Stream on a southbound Oleander transit in June 2005. The black curve at the top shows solar elevation. The red contours show speeds of 0.5 , 1.0 , and $1.5 \mathrm{~m} \mathrm{~s}^{-1}$ in the Gulf Stream, and -0.5 and $0.5 \mathrm{~m} \mathrm{~s}^{-1}$ in a cold core ring centered at $200 \mathrm{~km}$ (solid for positive velocity toward the northeast). The white contour shows the depth of an isolume, $I(z)=1 \times 10^{-7}$, which is unitless because it is a normalized value (i.e., when the sun elevation angle is directly overhead, the surface value, $I_{0}$ would be equal to 1$) . /(z)$ is calculated from the solar elevation angle and the diffuse attenuation coefficient, $k_{d}$, according to an exponential decay, $I(z)=e^{-k_{d} z}$, where $k_{d}$ at $490 \mathrm{~nm}$ is interpolated for the appropriate month along the path of Oleander from the SeaWifs satellite product. Therefore, the approximation of light here accounts for the climatological mean pattern of absorbing constituents in the water column, but does not account for cloudiness. The cross-Gulf Stream distance is calculated as in Thomas and Joyce (2010), which takes the maximum depth-averaged velocity as the center of the Gulf Stream and the direction of that velocity as perpendicular to the cross-stream direction. 